\title{
Corpus
}

Archivos virtuales de la alteridad americana

Vol 1, No 2 | 2011

Julio / Diciembre 2011

\section{Historia y silencio: La Conquista del Desierto como genocidio no-narrado}

Pilar Pérez

\section{(2) OpenEdition}

Journals

\section{Electronic version}

URL: http://journals.openedition.org/corpusarchivos/1157

DOI: 10.4000/corpusarchivos. 1157

ISSN: 1853-8037

\section{Publisher}

Diego Escolar

\section{Electronic reference}

Pilar Pérez, « Historia y silencio: La Conquista del Desierto como genocidio no-narrado », Corpus [En línea], Vol 1, No 2 | 2011, Publicado el 30 diciembre 2011, consultado el 10 diciembre 2020. URL : http://journals.openedition.org/corpusarchivos/1157 ; DOI : https://doi.org/10.4000/corpusarchivos 1157

This text was automatically generated on 10 December 2020. 


\title{
Historia y silencio: La Conquista del Desierto como genocidio no-narrado
}

\author{
Pilar Pérez
}

1 El campo de los estudios sobre genocidio ha venido creciendo sostenidamente desde principios de la década del noventa descentralizando el monopolio de la atribución de genocidio, y de los estudios al respecto, al holocausto. La principal ventaja de que exista este espacio de debate radica en su carácter interdisciplinario (ya que cuenta con contribuciones de la historia, sociología, derecho, ciencias políticas, antropología, demografía, entre otras). Estos enfoques enriquecen, sin duda, el estudio de un proceso social complejo que lejos de circunscribirse a un evento violento -aislado y con un fin concreto- requiere del análisis de múltiples niveles para ser comprendido y para sopesar su magnitud espacio temporal (Straus, 2006).

2 Por otra parte, la categoría genocidio es hoy invocada desde agencias muy distantes. En el caso argentino la denuncia por genocidio es sostenida por numerosas organizaciones indígenas y de derechos humanos para referir al proceso de incorporación de los pueblos originarios al estado nacional. Por otra parte, en términos de política internacional, la categoría está siendo apropiada desde estados poderosos, como los Estados Unidos aunque no solamente- para justificar intervenciones armadas en países del tercer mundo ${ }^{1}$ . Por esto, una preocupación central de los investigadores comprometidos con su estudio orbita en torno a la generalización indiscriminada del término. En gran medida porque al explicar diversos procesos como genocidas -la trata esclavista, la colonización, las dictaduras latinoamericanas de segunda mitad del siglo XX, etc- se corre el riego de diluir la especificidad del término o de equiparar procesos muy distintos entre sí.

Por supuesto existen numerosos intentos por clasificar los distintos tipos de genocidio. En este sentido, cabe destacar, por un lado, la trascendencia y, por otro, las constricciones que emergen de la Convención para la prevención y sanción del delito de genocidio propuesta por Raphael Lemkin y adoptada por la Asamblea General de las Naciones Unidas en 1948. Genocidio, resaltan numerosos especialistas en el tema, es un crimen antiguo al que se le otorgó un nombre por primera vez como consecuencia de los crímenes nazis (Kuper, 2002). 
4 En primer lugar, la Convención genera un piso de discusión común para pensar las acciones, los grupos y las responsabilidades en torno a un crimen perpetrado sobre un sector de la sociedad (ya no un individuo). Precisamente por este quiebre en el derecho liberal la Convención presenta numerosos problemas para su implementación en la justicia, como ha sido demostrado -por ejemplo- en el Tribunal Penal Internacional para Ruanda (Magnarella, 2002). Más allá de los problemas de orden legal que la Convención genera en cortes nacionales e internacionales, el origen jurídico del término impone ciertos límites propios del lenguaje que impiden la profundización en los procesos particulares. Uno de estos límites estructurantes de los estudios sobre genocidio radica, a mi entender, en considerar al genocidio, en tanto crimen, como un fin en sí mismo y, en este sentido, reducir su estudio en demostrar la intencionalidad del mismo. De esta forma se asume la lógica del proceso jurídico que deja de lado el motivo por ser irrelevante para determinar al responsable del crimen. Sin embargo, para las ciencias sociales y humanas el motivo es parte funda-mental para comprender el proceso y su desenlace. De esta forma, Zygmunt Bauman (1989) propone pensar el genocidio ya no como un fin en sí mismo, sino más bien como un medio cuyo fin es cambiar radicalmente una sociedad y convertirla en algo mejor. En consecuencia, el genocidio es parte constituyente de un proyecto a futuro.

5 Ambos enfoques tienen mucho para aportar cuando se propone analizar el caso argentino. Pensar el genocidio como fin nos permite destacar políticas de estado concretas sobre una población singularizada y discriminada dentro de la matriz estadonación-territorio que se materializa sobre fines del siglo XIX. Mientras el genocidio como medio nos habilita a reflexionar sobre una ingeniería social determinada hegemónicamente por la elite nacional centrada en Buenos Aires y con un alcance temporal que abarca gran parte del siglo XX. En estas dos líneas se enmarca desde estudios recientes el pro-ceso que en Argentina se denominó "Conquista del Desierto".

\section{El genocidio como fin: civilización y barbarie}

6 Si bien desde principios de la década de 1870 el estado argentino comenzó una ofensiva militar hacia las "tierras de indios" no fue sino hasta fines de la misma cuando la organización burocrática del estado y las necesidades del modelo económico permitieron al estado quebrantar todos los acuerdos y tratados firmados con caciques representativos de parcialidades soberanas de las pampas (Briones y Carrasco, 2000) y avanzar militarmente sobre la Patagonia. La Conquista fue sustentada en principio por medio de la Ley de empréstitos para su financiamiento e ideológicamente fue fomentada por intelectuales orgánicos al proyecto institucional desde el Congreso Nacional. Paralelamente operó una singularización del "indio" como un otro salvaje, extranjero e indeseable -respecto del inmigrante blanco europeo-. El territorio bajo su poder sometía el potencial de las tierras argentinas en un desierto. En consecuencia el indio encarnaba lo indeseable de lo que la comunidad imaginada -construida desde el estado- esperaba para sus miembros (Lenton 2005).

7 Los indígenas a los que normalmente se les reconocían adscripciones étnicas-territoriales (araucanos, manzaneros, pampas, etc) comenzaron a ser nombrados simple-mente como "indio" -junto a una adscripción nacional "chileno" o "argentino"-, categoría que reunía las características ya mencionadas y que lo convertían no solo en un otro condenable sino también peligroso (Delrio 2005). El peligro que el indígena representaba operaba en 
diversos niveles. Desde la membrecía nacional encarnaba un agente posible de desintegración por su atribuido barbarismo o extranjería. Desde el poder soberano territorializado disputaba legitimidad a su autoridad por su sola presencia en el territorio $\mathrm{y}$, conjuntamente, era la muestra viva de la incapacidad del estado de garantizar el orden, los derechos de propiedad y en definitiva, el progreso. Como contracara, las campañas exitosas en el sur demostraron la capacidad del estado de terminar con el "problema del indio" y fueron motivo de legitimación en carreras políticas como la del propio Julio A. Roca.

8 El proceso de ocupación y sometimiento llevó cerca de 5 años, en los cuales el ejército argentino sentó fuertes y fortines estratégicos a lo largo del río Negro desde donde operativizó campañas sucesivas y garantizó el control de la Patagonia norte. La Conquista del Desierto fue seguida desde la prensa porteña y fue acompañada por numerosos intelectuales reconocidos de la época, escritores, fotógrafos, ingenieros, etc quienes buscaban en esta marcha ser parte de un capítulo fundante del estado nacional (Navarro Floria 2007) y que oportunamente logró sellar la idea de que la Argentina era un país distinto en Latinoamérica, esto es, libre de indios.

9 En tanto, otras marchas se iniciaban para los indígenas en Patagonia. Aquellos que sobrevivían a las embestidas militares eran trasladados de a pie por cientos de kilómetros hasta los fuertes que funcionaban como campos de concentración. Como revela el estudio de Enrique Mases (2002), en tanto nuevos polos productivos, como el norte azucarero o la región cuyana, demandaran fuerza de trabajo, hombres jóvenes -en su mayoría- eran deportados hacia esos centros para trabajar como mano de obra esclava. En el caso de las mujeres y las niñas, principalmente, eran trasladadas a Buenos Aires para ser utilizados como servidumbre en las casas de la alta sociedad. La obligación que estas familias receptoras tenían con los "indiecitos" era las de darle bautismo cristiano y por ende un nuevo nombre. Otro destino que tenían los hombres era el propio ejército y la marina para formar parte de las divisiones que iniciaban las campañas militares del norte del país. Finalmente algunos fueron conservados como piezas de museo en vida y también después de muertos en el Museo de La Plata (Añon Suárez, Harrison y Pepe 2008).

10 A medida que los mercados laborales fueron satura-dos, aquellos sin destino continuaron siendo hacinados en los campos de concentración que duraron hasta fines de la década del 80 -a pesar de que oficialmente las campañas terminaron con la rendición de Saihueque el 1 de enero de 1885-, respondiendo a necesidades puntuales de otros polos económicos del país. En tanto, se debatían diversas estrategias inconclusas para reubicar a los sobrevivientes, las tierras se repartían entre pobladores que cumplieran con las características deseables del ciudadano argentino y se "colonizaban" por grandes compañías que monopolizaban grandes extensiones de tierra.

11 En esta breve descripción que retoma algunos de los aportes más destacados del tema podemos reconocer en el proceso de ocupación y sometimiento los 5 actos que menciona el artículo 2 de la Convención sancionada por la ONU (para un análisis detallado ver Delrio et al 2010)

\section{El genocidio en relación a los pueblos originarios}

12 La categoría genocidio tiende a ser utilizada para denunciar procesos de sometimiento y expropiación de pueblos indígenas en todo el mundo, en general con el fin de reivindicar 
derechos y visibilizar situaciones de vulneración de los mismos. Sin embargo, dentro de la academia existen esfuerzos por darle un uso más acota-do, preciso y problematizado. En este sentido podemos destacar dos tendencias. En primer lugar, la utilización de categorías como etnocidio, culturicidio o limpieza étnica que reemplazan genocidio y buscan focalizar en el aspecto cultural para incluir procesos de violencia simbólica y aculturación. ${ }^{2}$

En segundo lugar, se distinguen los procesos según la relación constituida por el perpetrador. El parteaguas está centrado en los que se consideran genocidios colonialistas, de expansión y en detrimento de un otro externo. En este caso el perpetrador no necesariamente es un estado, sino que puede provenir de agencias particulares ${ }^{3}$. Por su parte, los genocidios modernos se caracterizan por la singularización por parte de un estado de un otro interno (Feierstein 2005, p.60). Es decir, cuando el estado quiebra el mandato fundacional de hacer vivir y provoca la muerte de un sector de la sociedad.

En relación a la Conquista del Desierto, en particular, en la búsqueda por clasificar comparativamente este proceso existen dos tendencias sobre las que pueden leerse recreados distintos supuestos que el propio genocidio instaló en la historia nacional y en el sentido común de la sociedad argentina en general. En primer lugar, la ausencia de responsables en la eliminación de los indígenas. Asimismo su asimilación a la civilización como destino indeclinable. En segundo lugar, y como consecuencia de la anterior, el confinamiento al pasado de la existencia de indígenas en el país y, por ende, la fragmentación del proceso histórico que, entre otras cosas, descontextualiza los procesos contemporáneos de reafirmación y etnogénesis (Escolar 2007).

Una primera tendencia es entender la Conquista como un etnocidio -reemplazando genocidio- haciendo énfasis sobre todo en la pérdida cultural, en la asimilación y, por ende, reforzando la idea del inevitable proceso de extinción. Siguiendo el planteo de Delrio (2010), de esta manera se suele, por un lado, restar importancia a la eliminación física concreta que produjeron las campañas militares de ocupación del espacio patagónico. Asimismo, se reitera la falta de intención de exterminio. Finalmente, se ratifica la incorporación forzada como vía inevitable en donde el estado solo colaboró con excesos- a acelerar. De esta forma, se confirma a través de la clasificación académica enfocada en la asimilación -con todas las dificultades que el término implica- lo que la generación del 80 proponía como parte de una política de estado.

En segundo lugar, se entiende el proceso de la Con-quista del Desierto como un genocidio colonialista. Si bien nos interesa analizar esta divisoria -que cuenta con un amplio consenso en los estudios comparativos de genocidio- para el caso argentino, creemos necesario hacer hincapié en que cuando se asume a priori que la Con-quista fue una guerra contra un otro externo se reinscriben las lecturas extranjerizantes, así como la invisibilización de este sector de la sociedad. Pero principalmente se relega al pasado la presencia indígena y se minimizan las consecuencias del genocidio que perduran hasta el presente. 


\section{El genocidio como medio para constituir una nueva sociedad}

17 Durante la ocupación militar los indios reducidos por el ejército fueron concentrados dentro del territorio patagónico en Valcheta, Chichinales, Choele-Choel y Roca principalmente. Muchos fueron clasificados, seleccionados y deportados desde estos campos y trasladados hasta los cuarteles de Retiro o hacia la Isla Martín García donde esperaban un nuevo destino. Sin embargo, los campos también representaron el espacio desde donde varios caciques que contaban con el reconocimiento previo del estado negociaron -en clara asimetría- condiciones de subsistencia, la posibilidad de recibir tierras, para aquellos que se reagruparon en su entorno (Delrio, 2005)4. Las condiciones de vida de aquellos que quedaban en los campos -muchos viejos y débiles- fueron denunciadas por misioneros salesianos, viajeros e inclusive por algunos militares. Pero fundamentalmente, los campos forman parte de la memoria social indígena.

De esta manera en una fecha tardía como noviembre de 1889, producto en parte de los debates sobre qué hacer con los sobrevivientes, la Comisión central de tierras y colonias informa al Ministro del Interior que

En las márgenes del Río Valchetas existen en la actualidad bajo la vijilancia de una Comisaría Policial, no menos de 500 indios sometidos; según informes fidedignos que esta comisión ha recogido, viven en la mayor miseria sin que haya esperanza de que se civilicen por falta de medios conducentes a ese fin. Esta comisión piensa que por humanidad y conveniencia del país debe modificarse este estado de cosas (...) No escapará a V.E. la importancia que para el país tiene la formación de una colonia en el corazón del desierto, con elementos que ya existen allí y que aseguran el éxito de la Colonia. No es posible todavía formar esas colonias con in-migrantes europeos, y son los indígenas bien organizados y vigilados los que prepararán las rutas por donde muy luego penetrará una civilización más completa. (AGN-DAI, Exp grales, 1889, legajo 25, exp, 7977)

19 Previo a la Conquista, los indígenas eran considerados un otro interno, es decir interno al territorio pretendido como nacional -pero escasamente conocido por el estado- pero externo a la membrecía argentina (Briones y Delrio, 2002). A partir de la constitución material de un estado de excepción en los campos de concentración, los indígenas de los campos son estructuralmente producidos como sujetos subalternos dentro de la norma que impone la matriz estado-nación-territorio. En la cita de la Comisión, se destaca esta contradicción en donde por un lado surge la necesidad humanitaria y como contra-cara se afirma que los indios -vigilados- serán quienes preparen el camino para la civilización en la cual no son incluidos, sea por falta de condiciones, sea porque se es-pera la llegada de otros (inmigrantes) mejor preparados. Esta práctica discriminatoria será reiterada sucesiva-mente a través de las inspecciones de tierras y será argumento central para justificar desalojos y corridas (Perez, 2009a). Resta aclarar que la creación de la colonia con indígenas no fue autorizada.

Por otra parte, nos estamos refiriendo a aquellos indios que son listados, cuantificados, vigilados, distribuidos y -eventualmente- racionados por el estado que son los que están en los campos. Tal como destacan Nagy y Papazian (2009) para el caso de Martín García los indios sometidos se encuentran presos no por crímenes o faltas contra la sociedad sino por ser indios. Sin embargo, existen también aquellos otros que permanecen por fuera de los campos que siguen perteneciendo al mundo de los salvajes, del desierto y por sobre 
todo, no tienen ninguna capacidad de negociar o reclamar asientos de tierra. Es decir que el campo se vuelve un umbral entre la civilización y la barbarie. El indio del desierto puede volver a caer en su estado de salvajismo si queda fuera del campo - como el espacio de disciplinamiento y control en donde el estado realiza su poder soberano-.

Retomando la metáfora de Agamben (2003), el indio corresponde a la figura del "hombrelobo". Su esencia reificada por el estado contiene la latencia de que puede volverse sobre su estado animal y de esta forma ser agente de la disolución de la civilización. Por esto, aquellos que están dentro de los campos despiertan reclamos "humanitarios", son seres humanos en terribles condiciones, pero al mismo tiempo no pueden dejar de ser vigilados, porque antes que humanos son indios. En contrapartida la razón de ser del estado y su legitimidad de ejercer violencia se materializa en su relación con este otro interno.

\section{Palabras finales}

El proceso genocida funda una relación entre el estado y el indio en donde este es construido estructuralmente como una excepción dentro de la matriz del estado. Esto que se produce en el momento histórico de la Conquista marcará la relación entre el estado y los indios como sus márgenes a lo largo del siglo XX. Según Das y Poole (2008) los márgenes son supuestos necesarios del esta-do, en donde este encuentra legitimidad para recrear su siempre incompleto "sistema de estado" (Abrams, 1988) y a través de cuyas prácticas y rutinas se reproduce la construcción imaginaria del estado (Ferguson y Gupta, 2002).

La falta de historización del proceso a lo largo de gran parte del siglo XX apoyó el discurso de la extinción, simplificó el proceso histórico de construcción del estado nacional y colaboró en eludir responsabilidades. Más aún, el silencio de la historia autorizó la reproducción de formas de violencia simbólica y física sobre los indígenas, las cuales en caso de emerger por su gravedad, como el caso de Rincón Bomba (Mapelman, 2010), aparecen como hechos aislados y disociados de una trayectoria de relación. También aparecen como hechos aislados los desalojos, relocalizaciones, arreos de personas, entre otras formas de violencia enmarcadas en actos (i)legales ejercidas sobre los indígenas con el aval de o por parte del estado a lo largo del siglo XX (Pérez, 2009b y 2011).

Paralelamente la historia incompleta o la ausencia de imágenes sobre la otra cara del proceso civilizatorio - parte inherente del mismo siguiendo la propuesta de Traverso (1997)- sostuvo la desconexión entre pasado y presente que fomentó el proceso de invisibilización -sea como estrategia indígena para evitar la discriminación o como parte del proyecto homogeneizador de la nación-que en la actualidad es fundamental para deslegitimar demandas por derechos y por tierras. Por otra parte, la sociedad argentina desconoce esta otra parte -o descree, ya que ha sido educada en asumir la extinción "natural" de los indios- del proceso de consolidación del estado-nación como producto de políticas concretas de las elites del siglo XIX que pensaban en una sociedad argentina homogénea, producida por el estado sobre su territorio soberano. 


\section{BIBLIOGRAPHY}

Abrams, P. (1988). Notes on the difficulty of studying the state. Journal of historical sociology, 1 (1), 58-89.

Agamben G (2003). Estado de Excepción. Homo sacer II. Valencia: Ed. Pre-Textos.

Añón Suárez M., P. Harrison y F. Pepe (2008) Identificación y restitución: Colecciones de restos humanos en el Museo de La Plata. La Plata: Ed GUIAS.

Bauman, Z. (1989) Modernity and the holocaust, Cornell: Cornell University Press

Briones C. y Carrasco M. (2000). Pacta sunt servanda. capitulaciones convenios y tratado con indígenas en Pampa y Patagonia (Argentina 1742-1880) Buenos Aires: IWGIA.

Briones C. y Delrio W. (2002). Patria sí, Colonias también. Estrategias diferenciales de radicación de indígenas en Pampa y Patagonia (1885-1900). En: A. Teruel, M. Lacarrieu y O. Jerez (Comps.) Fronteras, ciudades y estados, Tomo I. (pp. 45-78). Córdoba: Alción Editora.

Das, V. y D. Poole (2008). El estado y sus márgenes. Etnografías comparadas, en Cuadernos de antropología social, $\mathrm{N}^{\circ} 27,19-52$.

Delrio W. (2005). Memorias de expropiación. Sometimiento e incorporación indígena en la Patagonia (1872-1943). Bernal: Editorial Universidad Nacional de Quilmes.

Delrio, W., D. Lenton, M. Musante, M. Nagy, A. Papazian y P. Pérez. (2010). Discussing Indigenous Genocide in Argentina: Past, Present, and Consequences of Argentinean State Policies toward Native Peoples. Genocide Studies and Prevention 5, 2 August 2010, 138-159.

Delrio W. (2010). Del no-evento al genocidio. Eadem Untrake Europa, n 10.

Escolar, D. (2007). Los Dones Étnicos de la Nación. Identidades huarpe y modos de producción de soberanía en Argentina. Buenos Aires: Prometeo.

Feierstein D. (2005). Genocidio. la administración de la muerte en la modernidad, Buenos Aires: Eduntref

Ferguson J. y A. Gupta (2002). Spatializing states: toward an ethnography of neoliberal governmentality. American Ethnologist, 29 (4), 981-1002.

Kuper L. (2002) Genocide: its political use in the twentieth century. En A. Hinton (Ed.), Genocide. An anthropological reader, Malden, Mass.: Blackwell

Lenton, D. (2005). De centauros a protegidos. La construcción del sujeto de la política indigenista Argentina desde los debates parlamentarios (1880-1970). Tesis doctoral, Universidad de Buenos Aires.

Magnarella, P. (2002). Recent development in the international law of genocide: an anthropological perspective on the international criminal tribunal for Rwanda. En: A. Hinton (Ed.), Annihilating difference. The Anthropology of Genocide.(pp. 310-322) California: University of California Press.

Mapelman, V. (2010) “Octubre pilagá”. Documental. 80’. Buenos Aires.

Mases E. (2002) Estado y cuestión indígena. El destino final de los indios sometidos en el fin del territorio (1878-1910).Buenos. Aires: Prometeo libros/Entrepasados. 
Nagy M. y A. Papazian (2009). De la Isla como Campo. Prácticas de disciplinamiento indígena en la Isla Martín García hacia fines s. XIX. XII Jornadas Interescuelas-Departamentos de Historia. Bariloche: Universidad Nacional del Comahue.

Navarro Floria, P. (2007). Paisajes del progreso. La resignificación de la Patagonia Norte, 1880-1916. Neuquén: Educo

Pérez, P. (2009a). Inspectores y “escribanos". Archivos y memorias de disputas territoriales mapuche en Río Negro en la primera mitad del siglo XX. Buenos Aires: VIII Reunión de Antropología del Mercosur.

Pérez, P. (2009b). Las policías fronterizas: mecanismos de control y espacialización en los territorios nacionales del sur a principios del siglo XX. XII Jornadas Interescuelas de Historia, Bariloche: Universidad Nacional del Comahue.

Pérez, P. (2011). Cuatreros, comerciantes, comisarios. Poder y capital en las primeras décadas del siglo XX en Río Negro. IV Jornadas de Historia Social de la Patagonia. Santa Rosa, 19 y 20 de Mayo

2011. UNLPam

Straus, S. (2006). The Order of Genocide: Race, Power, and War in Rwanda. Ithaca, NY: Cornell University Press.

Totten, S., Parsons, W. y Hitchcock, R. (2002). Confronting genocide and ethnocide of indigenous peoples. En: A. Hinton, Annhiliating difference. The Anthropology of Genocide.(pp. 54-91). California: University of California Press

Traverso, E. (1997). La historia desgarrada. Ensayo sobre Auschwitz y los intelectuales, Barcelona: Herder.

\section{NOTES}

1. Para un análisis detallado sobre el M.A.R.O. (Mass Atrocity Response Operations; A Military Planning Handbook) producido por el actual gobierno de EEUU ver el número especial de Genocide Studies and Prevention vol 6, 2011

2. Según los casos seguidos por Totten, Parsons y Hitchcock (2002), se suele avalar estas categorías para expresar la supresión física involuntaria, por ejemplo, la mortandad de indígenas por viruela en el contexto de la Conquista de América. Al mismo tiempo se utiliza etnocidio para procesos de asimilación forzada con la intención de "civilizar" o re-educar como suele caracterizarse el caso de las escuelas residenciales en Canadá.

3. Por ejemplo las compañías comerciales en tiempos coloniales que explotan determinados recursos (incluida la mano de obra) y que como consecuencia socavan la subsistencia de un determinado grupo social

4. Quizás otra vía para negociar reconocimientos por parte del estado correspondía al haber prestado servicios en las campañas. 


\section{AUTHOR}

\section{PILAR PÉREZ}

IIDyPCA-Universidad Nacional de Río Negro-Consejo Nacional de Investigaciones Científicas y Técnicas (CONICET), Argentina.

Correo electrónico: pezpil@gmail.com 